\title{
Adhesion to Dentin in Permanent Teeth - in vitro Study of the Border Zone and Bond Strength in Total-Etch Adhesives
}

\author{
Gateva $\mathbf{N}^{\mathrm{a}}$, Gusyiska $\mathbf{A}^{1}$, Stanimirov $\mathbf{P}^{3}$, Kabaktchieva $\mathbf{R}^{4}$, Raichev $\mathbf{I}^{5}$ \\ ${ }^{1}$ Associate Professor in Department of Pediatric Dentistry, Faculty of Dental Medicine, MU, Sofia, Bulgaria \\ ${ }^{2,5}$ Assistant Professor in Department of Conservative Dentistry, Faculty of Dental Medicine, MU, Sofia, Bulgaria \\ ${ }^{3}$ Associate Professor of the Department of Oral and Maxillo-Facial Surgery, Faculty of Dental Medicine, Medical University - Sofia, \\ Bulgaria
}

${ }^{4}$ Professor in Department of Pediatric Dentistry, Faculty of Dental Medicine, MU, Sofia, Bulgaria

\begin{abstract}
The objective of this study was to analyze the thickness and characteristics of the hybrid layer (HL) in samples of permanent teeth by using the scanning electron microscopy (SEM) and to evaluate the strength of the adhesive bond after application of total-etch adhesive systems. Material and methods: 50 samples of permanent teeth were studied by assigning into two groups, depending on the type of the tested adhesive systems. The tested adhesive systems were the three-step total-etch system OptiBondFL (Kerr) and the twostep total-etch system Exite (Ivoclar Vivadent). The adhesive systems were applied according to the manufacturer's instructions. The samples were restored with a composite resin (TeEconom, Ivoclar Vivadent). For the purposes of SEM examination of the border zone, 5 samples of each group were subjected to thermal stresses (1,500 cycles at temperatures between $\left.5^{\circ}-55^{\circ} \mathrm{C}\right)$ and masticatory loads (150,000 cycles over intervals of 0.4 seconds). Then, the samples were cut in the middle, demineralized, deproteinized and dried. The dentine-adhesive border zone was studied by using SEM to evaluate the thickness and micro-morphologic characteristics of the hybrid layer. The bond strength was assessed by performing the macrotensile test. The destructed surfaces were studied by SEM to determine the type of failure. For the purposes of data processing, the statistical software program SPSS v.17.0 was used. Results: The SEM examination showed differences in the thickness and characteristics of the HL between the two generations of adhesive systems. The three-step adhesives provided reliably greater strength of adhesion to the dentin, compared to the two-step adhesives.
\end{abstract}

Keywords: total-etch adhesives, hybrid layer, adhesive layer, bond strength, permanent teeth, scanning electron microscopy (SEM)

\section{Introduction}

Adhesion to tooth structures is based on a process, in which the inorganic dental material is replaced by a synthetic plastic material ([39], [41]). This process includes two phases. The first phase involves removal of calcium phosphates, resulting in creation of microporosity on the enamel and dentinal surfaces. The second phase, called "phase of hybridization", involves infiltration and subsequent polymerization of the plastic material in the created superficial microporosity ([7], [8], [41]). In essence, both phases contribute to "sticking" of the adhesive to tooth structures. At the same time or following the chemical treatment (conditioning) of the dentin, the adhesive penetrates into the dentin. This adhesive forms an inner intermediate layer, called "hybrid layer". The hybrid layer is covered by a thin layer of the adhesive that binds the composite ([7], [27]).

The application protocol of total-etch adhesives includes, as a separate step, the application of an acid to remove the smear layer and polluting closures. Simultaneously, dentin demineralization to the depth of 0.5 to $7.5 \mu \mathrm{m}$ is realized. The peritubular dentin is removed preferentially, thereby leading to expansion of dentinal tubules and funnel shaping of their orifices ([35], [36]). Demineralization of intertubular dentin and disclosure of a network of collagen fibers occur to enable the formation of a hybrid layer ([15], [16], [18], [19], [36], [42]).

The complicated protocol on the application of three-step total-etch adhesives and the resulting errors have been partially overcome by the development of the next generations of adhesives with a simplified protocol ([13], [38]). The two-step total-etch adhesives combine the application of the primer and the bond in a single step, but retain the step of separate etching, with all the resulting risks ([13], [38], [41]).

Researchers have assumed that the formation of a hybrid layer on the border zone between the adhesive and tooth structures, and the presence of adhesive closures with lateral branches are the typical microscopic characteristics of effective bonding ([16], [18], [20], [34]). The quality of the formed hybrid layer is also of essential importance for the dentin bond strength ([10], [18], [19], [31]).

The objective of this in vitro study was to compare the strength of the adhesive bond to the dentin and to make a SEM characterization of the dentine-adhesive border zone and the type of destruction following the application of totaletch adhesives.

For achieving this goal, the following tasks were set: 


\section{International Journal of Science and Research (IJSR) \\ ISSN (Online): 2319-7064}

Index Copernicus Value (2013): 6.14 | Impact Factor (2014): 5.611

- To make descriptive characteristics of the studied adhesive-dentin border zone.

- To measure the thickness of the HL in the samples.

- Following the application of the total-etch adhesive systems, to compare the bond strength after performing the macrotensile test.

- To compare the type of destruction by using a scanning electron microscope.

\section{Materials and Methods}

The study included 50 samples of intact permanent premolars and molars. Permanent teeth were collected from healthy subjects, aged 50-65 years, after obtaining signed informed consents. The teeth were extracted because of periodontal problems. After extraction, the teeth were placed in $10 \%$ formalin solution for 10 minutes and stored in saline solution until the time of testing.

\section{Preparation of tooth surfaces}

The occlusal enamel surface of each tooth was removed to the depth of $1.5 \mathrm{~mm}$ below the central fissure by using a fissure diamond bur, turbine and water-air cooling. The samples were examined by using the optical microscope OLYMPUS VANOX-T, under magnification from $25 \mathrm{x}$ to $100 \mathrm{x}$, to establish whether the enamel was completely removed from the occlusal surfaces. The adhesive systems were applied according to the manufacturer's instructions and are presented in Table 1.

\section{Preparation of the samples for SEM examination of the border zone}

Five samples of each group were restored with the photopolymerizable material TeEconom (Ivoclar Vivadent, color A3) that was applied and polymerized layer by layer each layer with thickness of $1.5 \mathrm{~mm}$. The polymerization was carried out with the photopolymer lamp Coltolux 75, Curing Light, Coltène Whaledent. The restored samples were subjected to thermal stresses at temperatures ranging from $5^{\circ} \mathrm{C}$ to $55^{\circ} \mathrm{C}$ for 1,500 cycles and to masticatory loads of $100 \mathrm{~N}$ for 150,000 cycles over intervals of 0.4 seconds. The distribution of samples by groups and adhesive systems is presented in Table 1.

Table 1: Distribution of samples by groups, according to the type of the adhesive system used

\begin{tabular}{|l|l|l|l|}
\hline Group & Samples & Adhesive system & Type \\
\hline Group 1 & $\mathrm{n}=25$ & OptiBondFL (Kerr) & 3-step \\
\hline Group 2 & $\mathrm{n}=25$ & Exite (Ivoclar Vivadent) & 2-step \\
\hline
\end{tabular}

The restored samples were cut in the middle, in the mesialdistal direction, by using a diamond blade (ISO 350514220 ) and water cooling. The samples were decalcified with $36 \%$ silicon-free phosphoric acid for 10 seconds and deproteinized with 5\% hypochlorite for 120 seconds. The so-prepared samples were washed with waterair jet for 15 seconds, dried on paper and placed in a desiccator for 24 hours.

Preparation of restorations for testing the bond strength For preparing comparable and predictable surfaces of the restorations, commercially available copper rings (No. 15) with height of $5 \mathrm{~mm}$ and diameter of $5 \mathrm{~mm}$ were used. Thus, the same geometry of the studied border zone and the same height of the restoration were provided in all samples.

In all samples, the etching and the applying of the adhesive system were made centrally on the exposed dentinal surface, on a surface with diameter comparable to that of the copper ring. The pre-prepared copper ring was placed on the prepared dentinal surface. A layer of the photopolymerizable composite resin (Tetric EvoCeram, Ivoclar Vivadent, color A3) with thickness of up to $2 \mathrm{~mm}$ was placed within this ring and then polymerized with UV light for 40 seconds by using a photopolymer lamp (Coltolux 75, Curing Light, Coltène Whaledent). Then, a metal loop of orthodontic wire (No. 0.8) with length of about $10 \mathrm{~mm}$ was placed perpendicularly to the cut of the occlusal surface, in the center of the ring, and an additional amount of photopolymerizable composite resin was applied to fill up the copper ring and fix the metal loop. Polymerization with UV light for 40 seconds followed. The two free ends of each metal loop, which were placed in the copper ring and were covered by the photopolymerizable composite resin, were completed in a retention loop.

On the side of the pulp chamber, at the level of the cut roots, the entire pulp chamber was etched for 15 seconds, rinsed for 15 seconds, dried and coated with the three-step adhesive system. A layer of photopolymerizable composite resin was placed and polymerized for 40 seconds. A second metal loop was placed, similar to that on the occlusal surface in the copper ring. A photopolymerizable composite resin was added to fill the entire pulp chamber and polymerized for 40 seconds.

The prepared samples were stored in water at room temperature for 72 hours prior to testing.

\section{Testing the bond strength}

Measurements of the achieved bond strength were accomplished on a bench for physical and mechanical tests of the type INSTRON - 1185. The loading beam moved at the steady speed of $1 \mathrm{~mm} / \mathrm{min}$. The maximum resistance force causing detachment of the restoration from the occlusal dentinal surface was registered in $\mathrm{MPa}$. The test was terminated after complete destruction of the tested sample.

\section{Determining the type of bond destruction}

After performing the bond strength test, the samples were dehydrated for 1 hour in ascending ethanol concentrations of $75 \%, 95 \%$ and $100 \%$, respectively. After dehydration, the samples were placed on filter paper and covered with a glass cover for 24 hours.

Both halves of each sample were examined by SEM under magnifications of up to 1500 , to determine the type of bond destruction.

The bond destruction of each sample was classified in one of the following types:

Type 1: adhesive fracture - the fracture line run within the adhesive on the dentin-adhesive border zone and on the composite-adhesive border zone - adhesive remnants were 


\section{International Journal of Science and Research (IJSR) \\ ISSN (Online): 2319-7064 \\ Index Copernicus Value (2013): 6.14 | Impact Factor (2014): 5.611}

observed on both sides of the tooth and on the ring - this was a failure in adhesion.

Type 2: cohesive fracture in the composite - the fracture line run within the composite only.

Type 3: cohesive fracture in the dentin - the fracture line run within the dentin only.

Type 4: mixed fracture - the samples showed both types of fracture - adhesive and cohesive destruction - dentinadhesive-composite.

\section{Preparation of samples for SEM examination}

All samples were placed on aluminium cylinders, previously vacuum-coated with gold dust in an argon medium - cathode sputtering (JEOL JFC - 1200 Fine coater). The examinations were made by using the scanning electron microscope JEOL JSM - 5510 SEM, under magnification of 18, 750 to 1500. Scans of the adhesive-tooth structure border zone for examining and evaluating the morphology of the adhesive and hybrid layer and the adhesive tags, and scans of the detachment zone for evaluating the type of failure were made.

The morphologic criteria, used for comparing, were as follows: thickness of the adhesive layer (AL), thickness and integrity of the hybrid layer (HL), formation of adhesive closures and their lateral branches. The thickness of the hybrid layer was measured on the scans by using graph paper and compasses at three different random points (at both ends and the center of each scan). The average value of these three measurements was calculated. Measurements, obtained in millimeters, were turned into microns.

\section{Results}

Scans of the border zone in the samples of both groups, examined by SEM, are presented on figures 1 to 6 .

The samples in group 1 were treated with the three-step, total-etch adhesive system OptiBond FL (Kerr) (Fig.1, 2, 3).

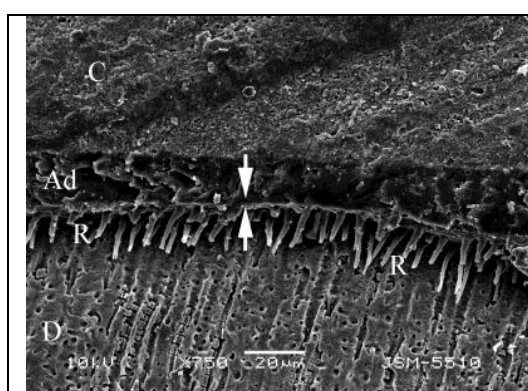

Figure 1

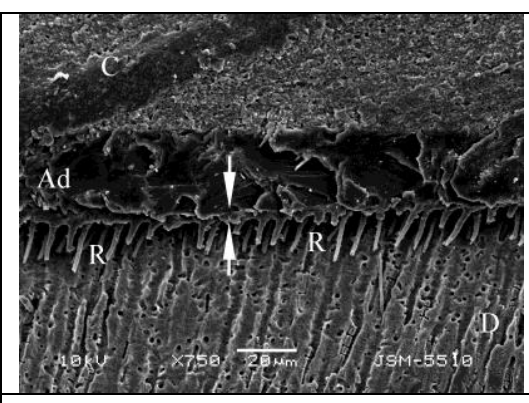

Figure 2

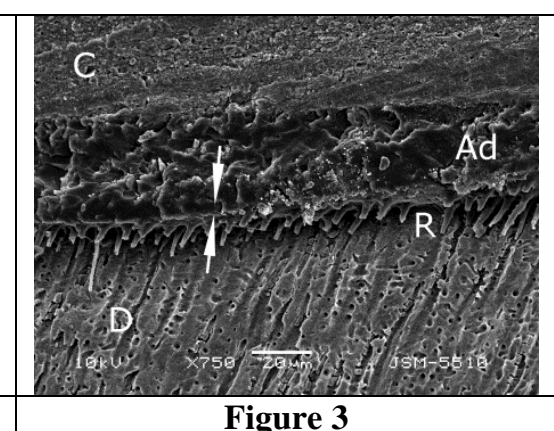

Figure 3

Figures 1, 2 and 3: SEM of the hybrid (between the arrows) and adhesive (Ad) layer within the dentin of a permanent molar (demineralized with $37 \%$ phosphoric acid for 15 seconds) and the adhesive system OptiBond FL (Kerr). Note the adhesive closures (R) in the dentin (D); C = composite.

The samples in group 2 were treated with the fifthgeneration, two-step, total-etch adhesive system Exite (Ivoclar Vivadent) (Figure 4, 5, 6).

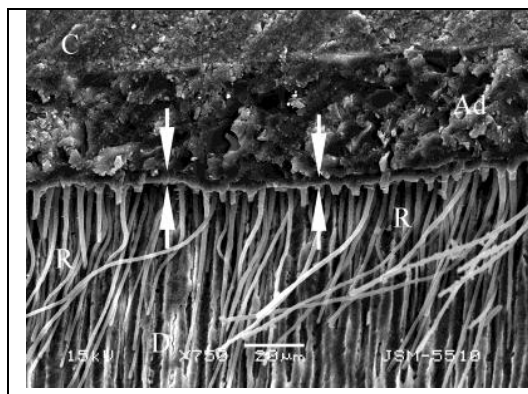

Figure 4

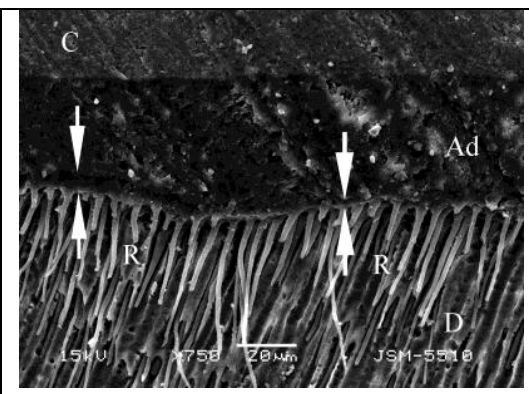

Figure 5

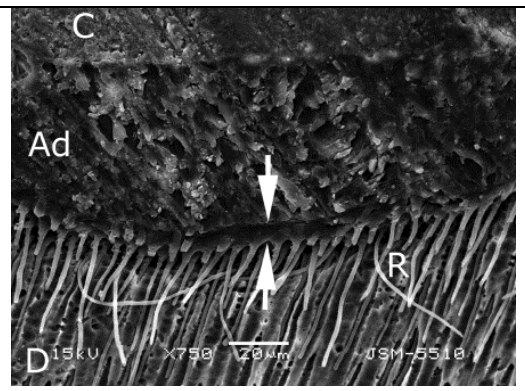

Figure 6

Figures 4, 5 and 6: SEM of the hybrid (between the arrows) and adhesive (Ad) layer within the dentin of a permanent molar (demineralized with $37 \%$ phosphoric acid for 15 seconds) and the adhesive system Exite (Ivoclar Vivadent). $\mathrm{R}=$ adhesive closures; $\mathrm{D}=$ dentin; $\mathrm{C}=$ composite

The scans allowed studying the thickness of the adhesive and the hybrid layer. The thickness was different between the samples of the same group, as well as the samples of both groups (Fig. $1-6$ ). The hybrid layer was thicker in the samples of group 2 (Fig. 4, 5, 6), compared to that in the samples of group 1 (Fig. 1, 2, 3). The thickness of the adhesive layer in the samples of group 2 (Fig. 4 - 6) was also greater than that in the samples of group 1 (Fig. 1 - 3).
Multiple funnel-shaped adhesive tags, penetrating into the hybrid layer, were observed as a result of the intratubular hybridization. These adhesive tags were more numerous in the samples of group 2 and penetrated deeper into the dentin, compared to group 1 (Fig. 1 - 6).

The observed characteristics and the average thickness of the HL in the samples of both groups are presented in Table 2. 


\section{International Journal of Science and Research (IJSR) \\ ISSN (Online): 2319-7064}

Index Copernicus Value (2013): 6.14 | Impact Factor (2014): 5.611

Table 2: Average thickness of the hybrid layer and characteristics of the adhesive layer and adhesive tags in the samples of both groups

\begin{tabular}{|c|c|c|}
\hline Group & Average thickness of hybrid layer & Adhesive layer, adhesive tags \\
\hline $\begin{array}{c}\text { Group 1 } \\
\text { OptiBondFL }\end{array}$ & $4,46 \pm 0,13$ & $\begin{array}{c}\text { Clearly visible adhesive layer of uniform thickness along the samples. } \\
\text { A lot of adhesive tags with a funnel shape at the base, entering at various depths. }\end{array}$ \\
\hline $\begin{array}{c}\text { Group 2 } \\
\text { Exite }\end{array}$ & $7,36 \pm 0,56$ & $\begin{array}{c}\text { Clearly visible adhesive layer thicker than that of the samples of Group 1. } \\
\text { A lot of adhesive tags with a funnel shape at the base, entering a very large depth. }\end{array}$ \\
\hline
\end{tabular}

The analysis of thickness measurements of the hybrid layer showed a statistically significant difference between the samples of the two studied groups (Table 3).

Table 3: Thickness of the hybrid layer in the samples of Group 1 and Group 2

\begin{tabular}{|c|c|c|c|c|}
\hline Group & $\begin{array}{c}\text { Number of } \\
\text { scanning images }\end{array}$ & $\begin{array}{c}\text { Thickness of HL }(\mu) \\
\text { mean } \pm \text { SD }\end{array}$ & $\mathrm{T}$ & $\mathrm{P}$ \\
\hline Group 1 & 15 & $4.46 \pm 0.13$ & 11.28 & $<0.0001^{*}$ \\
Group 2 & 15 & $7.36 \pm 0.56$ & & \\
\hline
\end{tabular}

* There is a statistically significant difference.

A statistically significant difference in the thickness of the hybrid layer was registered between the samples of the two studied groups. A statistically significant thicker hybrid layer $(\mathrm{p}<0.0001)$ was observed in the samples of Group 2, treated with two-step, total-etch adhesives (Fig. 4 - 6).

The values of the minimum, maximum and average bond strength in $\mathrm{MPa}$, after performing the macrotensile test, are presented in Table 4.

Table 4: Bond strength in MPa, as measured with the macrotensile test

\begin{tabular}{|c|c|c|c|c|c|}
\hline Group & Adhesive & Samples & \multicolumn{3}{|c|}{ Macrotensile strength (MPa) } \\
\cline { 4 - 6 } & system & & Mean \pm SD & Min. & Max. \\
\hline Group 1 & OptiBond FL & 20 & $19,32 \pm 2,88$ & 14,88 & 23,96 \\
Group 2 & Exite & 20 & $17,68 \pm 2,89$ & 11,54 & 21,96 \\
\hline
\end{tabular}

The results of the comparison between the average bond strengths, following the application of the two total-etch adhesive systems, are presented in Table 5.
Table 5: Average bond strengths in the two groups, treated with total-etch adhesives

\begin{tabular}{|c|c|c|c|c|}
\hline Group & Samples & Bond strength $(\mathrm{MPa})$ mean \pm SE & $T$ & $P$ \\
\hline Group 1 & 20 & $19.32 \pm 0.90$ & 1.27 & $>0.05$ \\
Group 2 & 20 & $17.68 \pm 0.91$ & & \\
\hline
\end{tabular}

In our study, the analysis of average bond strengths showed no statistically significant difference between the two types of adhesive systems ( $p>0.05)$ (Table 5). However, the threestep, total-etch adhesive system showed higher average bond strengths (group 1 versus group 2, Table 5). The evaluation results of the type of destruction, after performing the macrotensile test, are presented in Table 6.

Table 6: Distribution of the samples in both groups by the type of bond failure

\begin{tabular}{|c|c|c|c|c|c|c|c|c|}
\hline Group & \multicolumn{2}{|c|}{$\begin{array}{c}\text { Adhesive type } \\
\text { of destruction }\end{array}$} & \multicolumn{2}{c|}{$\begin{array}{c}\text { Cohesive type } \\
\text { of destruction }\end{array}$} & \multicolumn{2}{|c|}{$\begin{array}{c}\text { Mixed type of } \\
\text { destruction }\end{array}$} & \multicolumn{2}{|c|}{ Total } \\
\cline { 2 - 10 } & $\mathrm{n}$ & $\%$ & $\mathrm{n}$ & $\%$ & $\mathrm{n}$ & $\%$ & $\mathrm{n}$ & $\%$ \\
\hline $\begin{array}{c}\text { Group } \\
1\end{array}$ & 2 & 20.0 & 2 & 20.0 & 6 & 60.0 & 10.0 & 100 \\
\hline $\begin{array}{c}\text { Group } \\
2\end{array}$ & 3 & 30.0 & 1 & 10.0 & 6 & 60.0 & 10.0 & 100 \\
\hline Total & 5 & 25.0 & 3 & 15.0 & 12 & 60.0 & 20.0 & 100 \\
\hline
\end{tabular}

During the examination of the type of destruction, it was found that the mixed type of failure was the most common, while the cohesive type of failure was the rarest (Table 6).

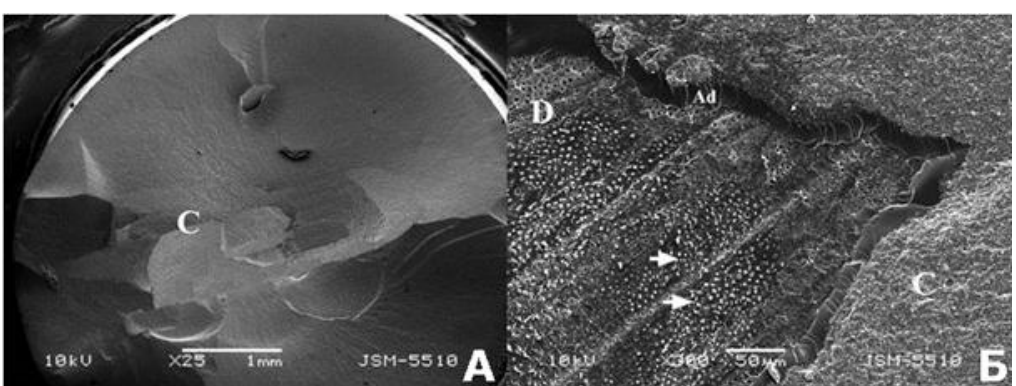

Figure 7: $\mathbf{A}$ / Cohesive type of destruction within the composite in the samples of Group 2. The fracture line runs within the composite $(\mathrm{C}=$ composite $)$ only. $\mathbf{B}$ / Mixed type of destruction - both adhesive and cohesive type of destruction within the composite. There is a dentinal surface (D) with partially opened dentinal tubules and dentinal tubules that are closed by adhesive tags (arrow). There is also a composite layer (C) onto the adhesive layer (Ad) - samples of Group 1.

\section{Discussion}

The descriptive analysis of the adhesive system-dentinal surface border zone showed that each of the applied adhesive systems has led to the formation of an interface zone - hybridization. This coincides with the results obtained by other researchers ([6], [18], [19], [21], [40]).

In addition, each of the tested adhesive systems has demonstrated own specific characteristics in terms of the thickness of AL, HL, the formation of adhesive tags and 


\section{International Journal of Science and Research (IJSR) \\ ISSN (Online): 2319-7064 \\ Index Copernicus Value (2013): 6.14 | Impact Factor (2014): 5.611}

their depth of penetration. A thicker hybrid layer and more adhesive tags, penetrating to the greatest depth, were observed in the samples of group 2 (Fig. 4 - 6), compared with those in group 1 (Fig. 1 - 3). It is believed that the adhesive tags contribute also to the dentin bond strength ([1], [26]). In total-etch adhesives, the formed tags increase by about one-third the total strength of the cutting ([1], [6], [14], [22], [26]). The shape of these adhesive tags is generally funnel-like, which is probably due to the fact that in the process of etching, some part of the peritubular dentin at the entrance of the tubule is removed and the tags bind the intratubular dentin near the zone of hybridization.

The differences in the morphology of the adhesive-dentin border zone may be due to the specific characteristics of the adhesive systems, which ultimately determine the ability of the adhesive system to wet and penetrate into the dentin ([23], [24], [29], [31]).

Micro-cracks were found in the samples of both groups, which may be due to the mechanical stress. We suggest that the preparation, polishing, demineralization and deproteinization of the samples, as well as the strong vacuum during the process of scanning, may also lead to the creation of artifacts and provoke changes on the tested border zone. The small number of samples in each study group did not present a risk of distortion of the results, the more so similar numbers of samples were sufficient for the conclusions of other researchers ([12], [33]).

The results obtained from the macrotensile test of the bond strength in the samples of both groups showed no statistically significant difference, but higher values - better strength, respectively, were registered in the samples of the first group (Table 5). These indicate that the type of applied adhesive system affects the achieved dentin bond strength.

In order to achieve effective dentin bond, the applied adhesive system should lead to the formation of a hybrid layer ([23], [32]). The quality of the hybrid layer is dependent on the $\mathrm{pH}$ of the etching agent, the ability of the polymeric monomer to infiltrate the demineralized dentin and the specific characteristics of the dentinal substrate ([2], [5], [7], [10], [23], [32]). According to some authors, however, the increase in the thickness of the hybrid layer is not associated with an increase in the bond strength. For achieving greater bond strength, the quality of this hybrid layer is more important, rather than its thickness ([10], [11], [18], [25]). This was also demonstrated in our study (Tables 3 and 5). A stable bond is achieved if the etched substrate was infiltrated entirely by the adhesive, while avoiding different degrees of incomplete impregnation ([17], [32]).

The present study shows that the type of adhesive system affects the achieved dentin bond strength. Shortening the protocol on the application of total-etch adhesive systems tends to reduce the achieved dentin bond strength. The two step adhesive systems demonstrate lower average bond strength values, compared with the three-step adhesives (Table 5). These results coincide with the results reported by other authors ([8], [13], [39]).
Researching the type of bond failure, we found that the mixed type of bond failure was the most common (Table 6). The greater dentin bond strength would lead to a higher incidence of mixed or cohesive type of failure. The study of the type of failure provides important information for the analysis of bond strength test results, and the classification of the type of failure is an important observation ([3]).

The influence of other parameters of the study should also be pointed out - the design of the experimental set-up and experimental conditions, the skill of the operator, the storage of samples until the time of testing, the time of the sample storage in water until the time of testing. These all are factors that significantly affect the values obtained for the bond strength and the type of failure ([4], [9], [28], [30]). Studies have shown that in vitro bond strength tests are effective methods for the clarification of the physical strength of the adhesive system and are a very important tool for the prediction and development of the clinical presentation of these systems ([28], [30], [37]). Although not directly predicting the clinical presentation of adhesives, comparisons between individual groups of adhesives are valid and can be used in making clinical decisions ([37]).

\section{Conclusion}

The described SEM findings coincide with the study results of other authors ([6], [8], [23], [39]). The main conclusions that can be made are:

The specific chemical characteristics (composition) of an adhesive system affect the micro-morphologic characteristics of the border zone, as reflected by the observed morphologic differences between the tested adhesive systems. The studied adhesive systems do not guarantee complete sealing of the composite-dentin border zone in the studied in vitro groups of teeth.

The results of the statistical analysis on the thickness of the HL and the achieved adhesive bond strength and the results of the descriptive SEM analysis on the border zone and the type of failure show that total-etch three-step adhesives are superior to total-etch two-step adhesives in our study.

\section{References}

[1] Adebayo OA, Burrow MF, Tyas MJ. Bonding of onestep and two-step self-etching primer adhesives to dentin with different tubule orientations. Acta Odontol Scand 2008; 66: 159-168.

[2] Breschi L., Mazzoni A., Ruggeri A., Cadenaro M., Di Lenarda R., Dorigo EDS.: Dental adhesion review: Aging and stability of the bonded interface Dent Mater 2008; 24: 90-101

[3] Can-Karabulut D. et al.: Adhesion to primary and permanent dentin and simple model approach. Eur J Dent 2009; 3: 32-41

[4] Courson F. et al.: Bond strength of nine current dentine adhesive systems to primary and permanent teeth. J Oral Rehabil 2005; 32: 296-303

[5] De Munck J., Van Landuyt K., Peumans M., Poitevin A., Lambrechts P., Braem M., Van Meerbeek B.: A critical review of the durability of adhesion to tooth 


\section{International Journal of Science and Research (IJSR) \\ ISSN (Online): 2319-7064}

Index Copernicus Value (2013): 6.14 | Impact Factor (2014): 5.611

tissue: methods and results J Dent Res 2005; 84(2): 118132

[6] Drobac M., Stojanac I., Ramić B., Premović M., Petrović L.: Micromorphological characterization of adhesive interface of sound dentin and total-etch and self-etch adhesives. Med Pregl. 2015 Jan-Feb;68(12):10-16.

[7] Eick JD., Gwinnett AJ., Pashley DH., Robinson SJ.: Current Concepts on Adhesion to Dentin. Crit Rev Oral Biol Med 1997; 8(3): 306-335

[8] Eliades G., Watts DS., Eliades T: Dental hard tissues and bonding. Interfacial phenomena and related properties. Springer 2005, 89-122

[9] Fowler CS. et al.: Influence of selected variables on adhesion testing. Dent Mater 1992; 8: 265-269

[10] Hashimoto M. et al.: The Effect of Hybrid Layer Thickness on Bond Strength: Demineralized Zone of Hybrid Layer. Dent Mater 2000; 16: 406-411

[11] Hashimoto M., Ohno H., Kaga M., Sano H., Tay FR., Oguchi H. et al: Over-etching Effects on Micro-tensile Bond Strength and Failure Patterns for Two Dentin Bonding Systems. J Dent 2002; 30: 99-105

[12] Kaaden Chr., Schmalz G., Powers J. M.: Morphological characterization of the resin-dentin interface in primary teeth. Clin Oral Invest 2003; 7: 235-240 •

[13]Larson TD.: Using Multiple Bonding Strategies. Northwest Dent. 2015 94(1):33-39.

[14]Lohbauer U., Nikolaenko SA., Petschelt A., Frenkenberger R.: Resin Tags do not Contribute to Dentin Adhesion in Self-etching Adhesives. Journal of Adhesive Dentistry 20008; 10: 97-103

[15]Lopez GC., Baratieri VLN., Caldeira de Andrada MA., Vieira LCC: Dental adhesion: Present state of the art and future perspectives. Quint Int 2002; 33: 213-224

[16] Marshall GWJr., Marshall SJ., Kinney JH., Balooch M.: The Dentin Substrate: Structure and Properties Related to Bonding. J Dent 1997; 25(6): 441-458

[17] Nishitani Y, Yoshiyama M, Donnelly AM, Agee KA, Sword J, Tay FR, et al. Effects of resin hydrophilicity on dentin bond strength. J Dent Res. 2006;85:1016-21

[18] Nör JE., Feigal RG., Dennison JB., Edwards CA.: Dentin Bonding: SEM Comparison of the Resin-Dentin Interface in Primary and Permanent Teeth.J Dent Res 1996; 75(6): 1396- 1403

[19]Nör JE., Feigal RG., Dennison JB., Edwards CA.: Dentin Bonding: SEM Comparison of the Dentin Surface in Primary and Permanent Teeth. Ped Dent 1997; 19(4); 246-252

[20] Osorio R, Toledano M, De Leonardi G, Tay F. Microleakage and interfacial morphology of selfetching adhesives in class $\mathrm{V}$ resin composite restorations. J Biomed Mater Res B Appl Biomater. 2003; 66: 399-409.

[21] Pereira CN, Daleprane B, Barbosa PF, Moreira AN, de Magalhães CS. Qualitative evaluation of scanning electron microscopy methods in a study of the resin cement/dentine adhesive interface. Microsc Microanal. 2014;20:268-75.

[22] Pashley DH., Ciucchi B., Sano H., Carvalho RM., Russell CM.: Bond strength versus dentine structure: A modelling approach. Archives of Oral Biology 1995; 40: 1109-1118
[23] Pashley DH, Tay FR, Breschi L, Tjäderhane L, Carvalho RM, Carrilho M, et al. State of the art etchand-rinse adhesives. Dent Mater 2011;27:1-16.

[24] Pashley DH, Tay FR, Carvalho RM, Rueggeberg FA, Agee KA, Carrilho M, et al. From dry bonding to waterwet bonding to ethanol-wet bonding. A review of the interactions between dentin matrix and solvated resins using macromodel of the hybrid layer. Am J Dent. 2007;20:7-21.

[25] Perdigão J., Lopes M.: The Effect of Etching Time on Dentin Demineralization. Quintessence Int 2001; 32: 19-26

[26] Phrukkanon S, Burrow MF, Tyas MJ. The effect of dentine location and tubule orientation on the bond strengths between resin and dentine. Journal of Dentistry 1999;27: 265-74.

[27] Rauch RU., Losche GM., Rosansky J., Roulet JF.: Comparison of quantitative margin analysis and dye penetration. J Dent Res 1996; 75: abstr.187; 41

[28] Salz U., Bock T.:Testing adhesion of direct restoratives to dental hard tissue - a review. J Adhes Dent. 2010 Oct; $12(5): 343-71$

[29] Sauro S, Watson TF, Manocci F, Miyake K, Huffman BP, Tay FR, et al. Two-photon laser confocal microscopy of micropermeability of resin-dentin bonds made with water or ethanol wet bonding. J Biomed Mater Res Part B Appl Biomater.2009;90B:327-37.

[30] Sirisha K., Rambabu T., Shankar Y.R., Ravikumar P.:Validity of bond strength tests: A critical review: Part I J Conserv Dent. 2014 Jul-Aug; 17(4): 305-311.

[31] Spencer P. et al.: Molecular Structure of Acid-Etched Dentin Smear Layers - in situ Study. J Dent Res 2001; 80(9): 1802-1807

[32] Takagaki T, Nikaido T, Tsuchiya S, Ikeda M, Foxton RM, Tagami J. Effect of hybridization on bond strength and adhesive interface after acid-base challenge using 4META/ MMA-TBB resin. Dent Mater J. 2009;28(2):185-93.

[33] Tanumiharja M, Burrow MF, Tyas MJ, Carpenter J: Field-emission scanning electron microscopy of resindentin interface morphology of seven dentin adhesive systems. J Adhes Dent 2000; 2: 259-269

[34] Toledano M, Osorio R, Albaladejo A, Aguilera FS, Osorio E. Differential effect of in vitro degradation on resin-dentin bonds produce by self-etch versus totaletch adhesives. J Biomed Mater Res A. 2006; 77: 128135.

[35] Van Meerbeek B., Conn LJr., Duke E., Eick J., Robinson S., Guerrero D.: Correlative transmission electron microscopy examination of nondemineralized and demineralized rezin-dentin interfaces formed by two dentin adhesive systems. J Dent Res 1996; 75: 879888

[36] Van Meerbeek B, Inokoshi S, Braem M, Lambrechts P, Vanherle G. Morphological aspects of the resin-dentin interdiffusion zone with different dentin adhesive systems. J Dent Res 1992;71:1530-1540.

[37] Van Meerbeek B., Peumans M., Poitevin A., Mine A., Van Ende A., Neves A., De Munck J.: Relationship between bond-strength tests and clinical outcomes. Dent Mater. 2010 Feb;26(2):e100-121.

[38] Van Meerbeek B., Van Landuyt K., De Munck JD., Hashimoto M., Peumans M., Lambrechts P., Yoshida 


\section{International Journal of Science and Research (IJSR) \\ ISSN (Online): 2319-7064}

Index Copernicus Value (2013): 6.14 | Impact Factor (2014): 5.611

Y., Inoue S., Suzuki K.: Technique-Sensitivity of Contemporary Adhesives. Dent Mater J 2005; 24(1): 113

[39] Van Meerbeek B., De Munck J., Yoshida Y., Inoue S., Vargas M., Vijay P. et all: Buonocore memorial lecture. Adhesion to enamel and dentin: current status and future challenges. Oper Dent 2003; 28: 215-235

[40] Van Meerbeek B, Vargas M, Inoue S, Yoshida Y, Perdigão $\mathrm{J}$, Lambrechts $\mathrm{P}$, et al. Microscopy investigations. Technique, results, limitations. Am J Dent. 2000;13:3D-18D.

[41] Van Meerbeek B.,Vargas M., Inoue S., Yoshida Y., Peumans M Lambrechts P. et all.: Adhesives and cements to promote preservation dentistry. Oper Dent 2001; 6: 119-144

[42] Wang Y., Spencer P.: Analysis of Acid-Treated Dentin Smear Debris and Smear Layers Using Confocal Raman Microspectroscopy. J Biomed mater Res. 2002; 60: 300308 